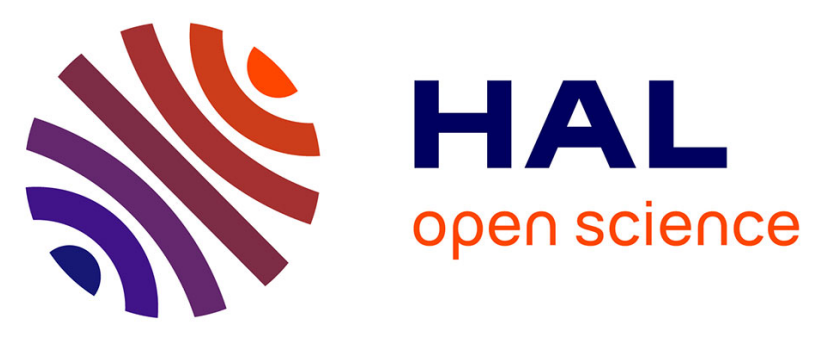

\title{
Amplitude and phase measurements of femtosecond pulses shaped using spectral hole burning in free-base naphthalocyanine-doped films.
}

S. Fraigne, Jean-Pierre Galaup, Jean-Louis Le Gouët, Manuel Joffre, Lionel

Canioni, Bruno Bousquet, Jean-Pierre Likforman

\section{To cite this version:}

S. Fraigne, Jean-Pierre Galaup, Jean-Louis Le Gouët, Manuel Joffre, Lionel Canioni, et al.. Amplitude and phase measurements of femtosecond pulses shaped using spectral hole burning in free-base naphthalocyanine-doped films.. International Conference on Ultrafast Phenomena, May 2002, Vancouver, Canada. pp.TuE1. hal-00991589

HAL Id: hal-00991589

https://hal-polytechnique.archives-ouvertes.fr/hal-00991589

Submitted on 15 May 2014

HAL is a multi-disciplinary open access archive for the deposit and dissemination of scientific research documents, whether they are published or not. The documents may come from teaching and research institutions in France or abroad, or from public or private research centers.
L'archive ouverte pluridisciplinaire HAL, est destinée au dépôt et à la diffusion de documents scientifiques de niveau recherche, publiés ou non, émanant des établissements d'enseignement et de recherche français ou étrangers, des laboratoires publics ou privés. 


\title{
Amplitude and phase measurements of femtosecond pulses shaped using spectral hole burning in free-base naphthalocyanine-doped films
}

\author{
S. Fraigne, J.-P. Galaup, J.-L. Le Gouet \\ Laboratoire Aimé Cotton, CNRS UPR 3321, Université Paris-Sud, Bât. 505, 91405 Orsay cedex, France \\ M. Joffre \\ Laboratoire d'Optique et Biosciences, CNRS UMR 7645 - INSERM U451-Ecole Polytechnique -ENSTA, \\ EcolePolytechnique 91128 Palaiseau Cedex, France \\ L. Canioni , B. Bousquet \\ Centre de Physique Moléculaire Optique et Hertzienne, Université Bordeaux I, CNRS UMR 5798, 33405 Talence Cedex, France \\ J.-P. Likforman \\ Laboratoire d'Optique Appliquée, CNRS UMR 7639 - INSERM U451 -Ecole Polytechnique -ENSTA, \\ Ecole Polytechnique 91128 Palaiseau Cedex, France \\ Present address: Institut de Physique et Chimie des Matériaux de Strasbourg, Groupe d'Optique Non-Linéaire et d'Optoélectronique, \\ CNRS UMR 7504, Université Louis Pasteur, 23, rue du Loess, B.P. 20CR, 67037 Strasbourg Cedex \\ Phone 333881071 93, Fax 33388107245 \\ jean-pierre.likforman@ipcms.u-strasbg.fr
}

Spatio-temporal holography using persistent spectral hole-burning in dye molecules embedded in plastic films is promising for applications such as femtosecond pulse shaping, data storage or phase conjugation. In addition to the common 2 spatial dimensions of classical holograms, each point in the sample plane can be used to store spectral informations such as the shape of a femtosecond pulse. On each point of the sample, spectral interferences between a reference pulse and an object pulse (for example chirped) are recorded via spectral hole-burning in the absorption band of the dye molecule. As early as 1983, photon echo and time-reversal experiments using persistent spectral hole-burning were performed in porphyrazine styrol solutions at $630 \mathrm{~nm}$ [1]. Then several developments, like the reconstruction of the polarization state of object pulses [2], time and space holography [3,4], image holograms using a single pair of femtosecond pulses [5] were demonstrated in different photosensitive media.

Few spectral holography experiments are done in the frequency domain of Titanium:Sapphire (Ti:S) lasers [5,6]. And, to our knowledge, none demonstrated the control of the phase of femtosecond pulses shaped using spectral holography based on persistent spectral hole-burning.

In this work we use a technique of spectroscopy adapted for measuring the amplitude and phase of photon echo signals [7] produced by diffraction of a fs pulse on a spectral hologram. We also improved the technique in terms of spectral resolution in order to measure photon echoes delayed by a few tens of picoseconds. Our study is focused on measuring the coherence time of the sample using a photon echo experiment in the photochemically accumulated regime and on demonstrating the pulse-shaping and time-reversal potentialities of our photo-sensitive material. Spectral holograms are formed through persistent spectral hole burning using a sequence of 2 pump pulses separated by a time delay, in a collinear geometry. The sample is a free base naphtalocyanine embedded in polyvinylbutyral $\left(\mathrm{H}_{2} \mathrm{NPc} / \mathrm{PVB}\right)$. The absorption peaks at $783 \mathrm{~nm}$ and is $20 \mathrm{~nm}$ large (FWHM). Our laser source is a $15-\mathrm{fs}, 100 \mathrm{MHz}$, Ti:S oscillator. 


\section{TuE1-2}

We performed a simple experiment that demonstrates the ability of $\mathrm{H}_{2} \mathrm{NPc} / \mathrm{PVB}$ for pulse shaping and time reversal. The experiment consists in introducing a chirp on one of the two pump pulses and engraving, in the absorption band, the spectral interferences between the chirped and unchirped pulses. Then the chirped (unchirped) pulse can be recovered by diffraction on the spectral hologram of the unchirped (chirped) pulse.

To change the sign of the spectral phase that we want to engrave in the sample, we simply change the time ordering between the two pulses, thus achieving time reversal. The amplitude and phase of the diffracted pulse are shown on the figure.

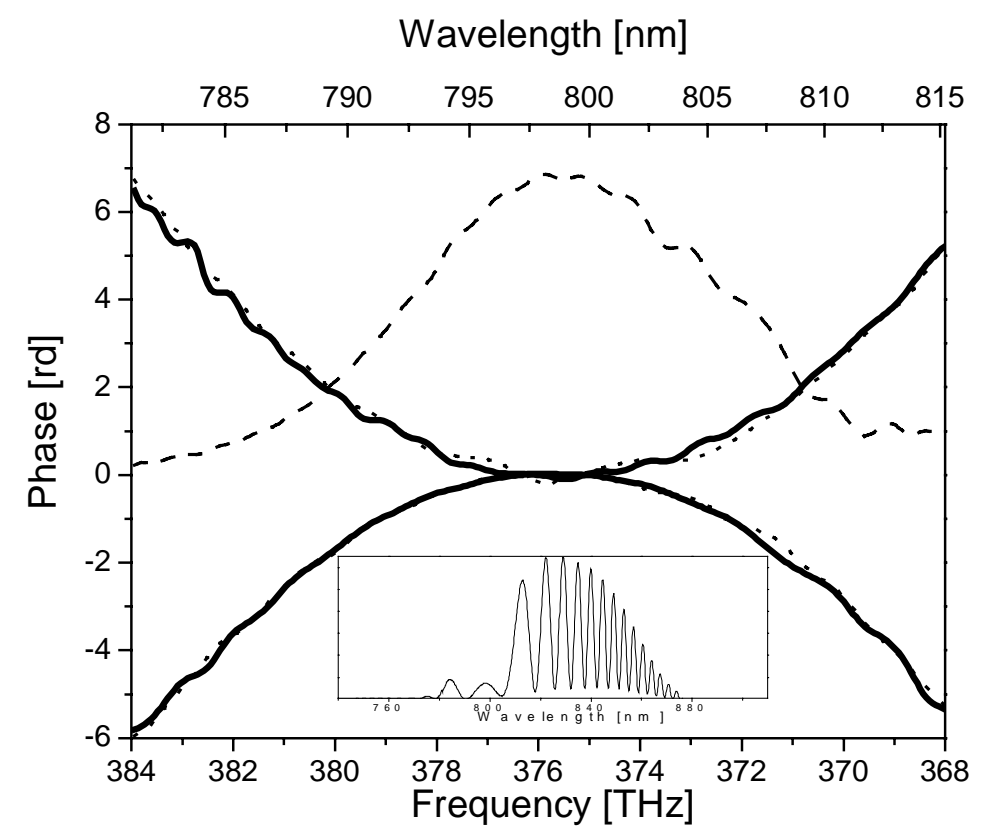

Fig. Solid lines: spectral phase of the diffracted pulse for two delays $+\tau$ and $-\tau$ between the writing pulses. Thin dotted lines : spectral phase difference between the 2 writing pulses for the two cases $+\tau$ and $-\tau$. We also show as a thin dashed line the diffracted pulse spectral amplitude. Inset: spectral interference fringes between the unchirped and chirped writing pulses at time delay equal 0 at $800 \mathrm{~nm}$. The chirp is formed by propagation through a SF58 glass plate of thickness $1.7 \mathrm{~cm}$.

We will also present our technique for measuring the amplitude and phase of photon echo signals formed with a time separation between the incident pulses of tens of picoseconds.

The next step for this kind of experiment is to write spectral holograms of arbitrary shape using a tunable cw source

[1] A. Rebane, R. K. Kaarli, P. M. Saari, A. Anijalg, K. Timpmann, Opt. Commun. 47, 173

[2] R. K. Kaarli, P. M. Saari, H. R. Sonajalg, Opt. Commun. 65, 170 (1988).

[3] P. Saari, R. Kaarli, A. Rebane, J. Opt. Soc. Am B 3, 527 (1986)

[4] A. Rebane, J. Aaviksoo, J. Kuhl, Appl. Phys. Lett. 54, 93 (1989).

[5] A. Rebane, M. Drobizhev, C; Sigel, Opt. Lett. 25, 1633 (2000).

[6] A. Rebane Opt. Commun. 147, 429 (1998).

[7] M. F. Emde, W. P. de Boeij, M. S. Pshenichnikov, D. A. Wiersma, Opt. Lett. 22,1338 (1997) 